\title{
Treatment of Hookworm.
}

\author{
M. P. Thornton.
}

$7 \mathrm{HE}$ commencement of the campaign against hookworm infection in the Purulia Leper Homes began in 1929, when the responsibility for treatment was handed over to the Sister in charge of the hospital. Previous to this time the method of procedure was for all patientsin the homes, including the children, to have one dose of carbon tetrachloride in March or April each year. The late Dr. Landeman was very dissatisfied with this method, as hardly any examinations were made, with the exception of a few severe cases of infection. He had all the inmates of the leper homes before him, house by house, and from these he collected the names of 372 patients who appeared to have severe hookworm infection. Subsequent examination of stools found all positive. These patients were treated a few at a time, and as they became negative others were put on the treatment list. All admissions to hospital were likewise treated, whether their names were on the list or not. (A good maxim for this hospital is to push the hookworm treatment in all septic cases and the troubles will clear up themselves.) These cases, at the rate of 6-12 examinations per day (the microscopical examinations being chiefly undertaken by Solomon Laurenga, the headcompounder) occupied the remaining months of 1929 and all of 1930. During 1931 Miss Krogh made an intensive campaign throughout the entire homes. All inmates were examined and treated where necessary. In 1932 I again took over the work, concentrating on new admissions to the homes, hospital patients, all children in the seven homes and some of the weekly out-patients.

In January, 1933, a systematic house by house examination was again commenced, and at the request of Dr. R. G. Cochrane, statistics were kept. At the beginning of each month a list was sent to hospital of all new cases. These are always put on the treatment list as soon as received. Hospital patients continue to be examined on admission, whether with a previous history of negative stools or not. Drs. Roy and Rao, and Solomon Laurenga, have done the microscopical work.

I did not manage to get all the cases examined last year but percentages to date show :-

Patients admitted before January 1st, 1933: 37.19\% H.W. ova positjve. 
Patients admitted after January 1st, 1933: 89.89\% H.W. ova positive.

Patients admitted after January 1st, 1933, for hospital treatment only: $70.83 \% \mathrm{H}$.W. ova positive.

(Some of these latter cases were given treatment before examination.)

626 patients were examined in 1933 . Of these, 318 were positive. The following is a list of the number of treatments required to produce negative stools.

\begin{tabular}{|c|c|c|c|c|c|c|}
\hline Narac & $\begin{array}{l}\text { 1st time discover- } \\
\text { ed H.W. Pos. }\end{array}$ & $\begin{array}{l}\text { No. of } \\
\text { doses } \\
\text { required }\end{array}$ & $\begin{array}{l}\text { For } \\
\text { 1st time } \\
\text { Neg. } \\
\text { Result }\end{array}$ & $\begin{array}{c}\text { Again } \\
\text { Pos. }\end{array}$ & Treated & Sulsequent examinations \\
\hline Mukta & $\left.\begin{array}{c}12 / 27 \\
1 / 28\end{array}\right\} \begin{array}{c}\text { Only } \\
\text { treattially } \\
\text { treated }\end{array}$ & 3 & $\begin{array}{c}7 / 29 \\
\text { Pxami.? } \\
\text { Faulty. }\end{array}$ & $\begin{array}{l}\text { '30, '31 } \\
\text { Treated } \\
\text { till clear } \\
13 \text { times }\end{array}$ & 2 & $/ 6 / 32, / 5 / 33, / 1 / 34$ \\
\hline Absalom & $/ 3 / 30$ & 1 & $/ 3 / 30$ & - & — & $/ 8 / 33, / 1 / 34$ \\
\hline Kusum & $/ 10 / 32$ & 5 & $14 / 33$ & - & - & /1/34 \\
\hline Sunimia $\ldots$ & $/ 11 / 30$ & (?) & $/ 1 / 30$ & - & - & $/ 6 / 31, / 1 / 34$ \\
\hline Magdolini ... & $/ 6 / 30$ & (?) & $/ 8 / 30$ & $/ 6 / 31$ & 1 & $/ 1 / 34$ \\
\hline Matongini & $/ 5 / 30$ & (?) & $/ 11 / 30$ & - & - & $/ 5 / 31, / 1 / 34$ \\
\hline Raphael ... & $/ 5 / 30$ & 1 & $/ 5 / 30$ & - & - & $/ 6 / 31, / 1 / 33, / 1 / 34$ \\
\hline XDulal $\ldots$ & $\mid 2 / 28$ & (?) & $/ 4 / 29$ & $/ 7 / 31$ & 2 & $/ 9 / 33, / 1 / 34$ \\
\hline Haradon ... & $/ 6 / 30$ & 2 & $/ 11 / 30$ & $/ 7 / 31$ & 1 & $/ 6 / 33, / 1 / 34$ \\
\hline Biswapoti & $/ 1 / 29$ & 2 & $/ 6 / 29$ & 1 & - & $/ 8 / 31, / 1 / 34$ \\
\hline Sarbananda & $/ 5 / 29$ & 3 & $/ 7 / 29$ & - & - & $\begin{array}{l}/ 11 / 29, / 1 / 31, / 8 / 31, \\
/ 8 / 33, / 1 / 34\end{array}$ \\
\hline Peter & $/ 8 / 30$ & 4 & $/ 11 / 30$ & - & - & $/ 7 / 31, / 6 / 33, / 1 / 34$ \\
\hline Khonka & $/ 7 / 30$ & (?) & $/ 11 / 30$ & - & - & $/ 8 / 31, / 9 / 32, / 7 / 33, / 1 / 34$ \\
\hline Baroda & $111 / 30$ & (?) & $/ 11 / 30$ & - & - & $/ 5 / 31, / 1 / 33$ \\
\hline Raya & $/ 3 / 32$ & 2 & $7 / 32$ & - & - & $/ 1 / 34$ \\
\hline Krishnadas & $7 / 30$ & 2 & $/ 9 / 30$ & - & - & $17 / 31, / 1 / 34$ \\
\hline Horipad ... & $/ 7 / 30$ & 5 & $/ 11 / 30$ & - & - & $/ 7 / 31, / 9 / 33, / 1 / 34$ \\
\hline Simson & $/ 11 / 29$ & (?) & $/ 6 / 30$ & $/ 7 / 31$ & 1 & $/ 5 / 33, / 1 / 34$ \\
\hline Sichoria ... & $/ 4 / 29$ & 10 & $/ 7 / 30$ & /1/34 & i & $/ 7 / 31, / 7 / 32,16 / 1 / 34$ \\
\hline Kironbala & 1927 & 14 & '30 & - & - & $31,32,33, / 1 / 34$ \\
\hline Daud $\ldots$ & $10 / 32$ & 8 & 33 & - & - & $/ 1 / 34$ \\
\hline
\end{tabular}

H.W. Treatments.-Carbon Tetrachloride m. 40.

Old Patients.

Cleared 88 with 1 treatment

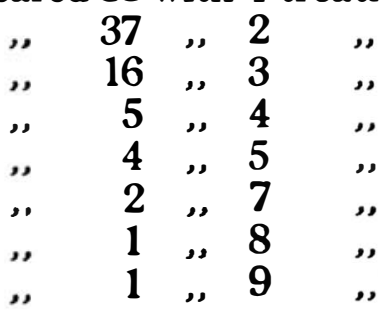

Out-patients and

New Admissions.

Cleared 30 with 1 treatment

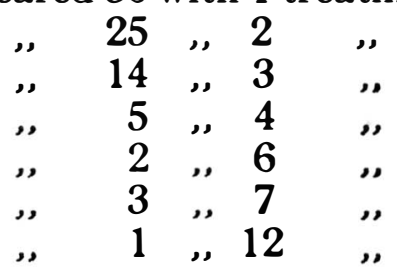

41 patients under treatment at present time.

The method of treatment is carbon tetrachloride, with three exceptions, when beta napthol grs. 40 was administered. The usual dose given of C.T. is m.40. In severe 
cases of weakness m. 30 was given as the initial dose. The carbon tetrachloride is mixed with an equal quantity of milk or rice-water and administered to the patient in this way : children according to age, a child of twelve taking $\mathrm{m} .20$ if normal size for age. I find the patients are less likely to vomit afterwards if the treatment is given in the morning after fasting all night. C.T. is followed one hour later by an ordinary dose of magnesium sulphate, except in the old or weak, when a smaller dose suffices. After an action of the bowels all patients are instructed to take one pao of milk (this is supplied to each one from hospital and is an encouragement to come along for treatment). I find the milk prevents any toxic effects from arising. One patient was troubled with vomiting for 24 hours. Subsequent information elicited the fact that he had not taken his milk as prescribed, but kept it for the evening. Mid-day he had his rice as usual. A similar patient in hospital had the same trouble for six hours. His milk was found in his locker. Both patients soon recovered when kept on milk for 24 hours.

An examination is made two weeks after treatment, positive cases continuing treatment and examinations in this manner until a negative stool is found. Cases requiring four treatments and over are examined again three months after a stool has been found negative. In two cases only have ova been found and this has cleared up entirely in one more treatment. Several persistent cases have had a long period free from infection, as particulars given in table will show. One casualty occurred, but whether due entirely to treatment by C.T. is uncertain.

A fairly new admission case had taken his treatment and returned to his house. Diarrhœa was reported the following day and unfortunately the man was not admitted to hospital, neither did I hear of his trouble until he collapsed and died before help was available. He had appeared in fairly good condition except for some anæmia.

Dr. R. G. Cochrane, during his physical examination of female patients in 1933, discovered a number of slight heart disorders. Practically all of these women had a history of previous hookworm infection and in some cases examination proved a present history.

I have found it worth while concentrating on a group of patients at a time until they are negative to hookworm ova, rather than giving treatment all round and then beginning all over again. Anæmic and new admissions are always put in the current treatment group. $30-60$ patients at a 
time are under treatment, additions being made as others pass on to the "negative" group. Treatment is on the whole much appreciated and is shown by the concern some patients show if they have not been called down for treatment after having delivered their specimen at the dispensary. Only this week I have two requests to give more treatment. One was from an ex-sepoy, who begged to have treatment once again and not to trouble to see whether it was needed or not. He said he felt so much better after the last course, that he wished to take another. Some little time ago we had difficulty in getting an old man back to his house because he was demanding treatment ! He said he had never felt so well in his life as he did the weeks after taking his two treatments. He was given Mist. Iron Tonic to quieten him. This latter is given for one month to all patients requiring three treatments or over. Some of the others have it too, if they appear anæmic. 